\title{
The Edwin Smith papyrus: a clinical reappraisal of the oldest known document on spinal injuries
}

\author{
Joost J. van Middendorp • Gonzalo M. Sanchez • \\ Alwyn L. Burridge
}

Received: 20 May 2010/ Accepted: 11 July 2010/Published online: 10 August 2010

(C) The Author(s) 2010. This article is published with open access at Springerlink.com

\begin{abstract}
Dating from the seventeenth century B.c. the Edwin Smith papyrus is a unique treatise containing the oldest known descriptions of signs and symptoms of injuries of the spinal column and spinal cord. Based on a recent "medically based translation" of the Smith papyrus, its enclosed treasures in diagnostic, prognostic and therapeutic reasoning are revisited. Although patient demographics, diagnostic techniques and therapeutic options considerably changed over time, the documented rationale on spinal injuries can still be regarded as the state-of-the-art reasoning for modern clinical practice.
\end{abstract}

Keywords Papyrus smith - Medical history ·

Spinal injuries $\cdot$ Spinal cord injuries

J. J. van Middendorp ( $\square$ )

Spine Unit, Department of Orthopaedics, Radboud University Nijmegen Medical Center,

P.O. Box 9101, 6500 HB Nijmegen, The Netherlands

e-mail: jvanmiddendorp@gmail.com

G. M. Sanchez

Department of Surgery, Neurosurgery,

University of South Dakota, 100 MacLane, Pierre, SD, USA

e-mail: gsanchez37@pie.midco.net

G. M. Sanchez

University of Arizona Egyptian Expedition, Tucson, AZ, USA

A. L. Burridge

University of Toronto, Ontario, Canada

e-mail: alwyn.burridge@sympatico.ca

\section{Introduction}

Dating from the seventeenth century в.c., the Edwin Smith papyrus is the oldest known surviving trauma text in history [1]. This ancient medical treatise is credited as containing the earliest known scientific writings on rational observations in medicine. A total of 48 cases are presented in the papyrus, of which six deal with injuries to the spine. The cases contain highly accurate descriptions of signs and symptoms of different types of spinal injuries.

The objective of this review was to reappraise the clinical descriptions of the spinal injury cases documented in the Edwin Smith papyrus. Whereas several previous reports focused on the translational details and controversies of the scroll [1-6], this study primarily aims to revisit its enclosed treasures in diagnostic, prognostic and therapeutic reasoning. Subsequently, these findings are placed in the context of the contemporary diagnostic work-up and classifications of spinal injuries.

\section{A brief summary of the history and translation of the papyrus}

After lying in a tomb in Thebes, Egypt, for over 3,000 years, the papyrus (Fig. 1) [7] was sold to the antiquities dealer Edwin Smith in 1862. Despite praiseworthy attempts, Smith did not manage to translate the scroll. After his death in 1906, the papyrus was donated to 'The New York Historical Society' by his daughter. It was not until 1920 the moment the papyrus was entrusted to the renowned Egyptologist James Henry Breasted for translation. After a long period of study and analysis Breasted accomplished the tremendous task of translating the papyrus and published a historic two-volume edition 


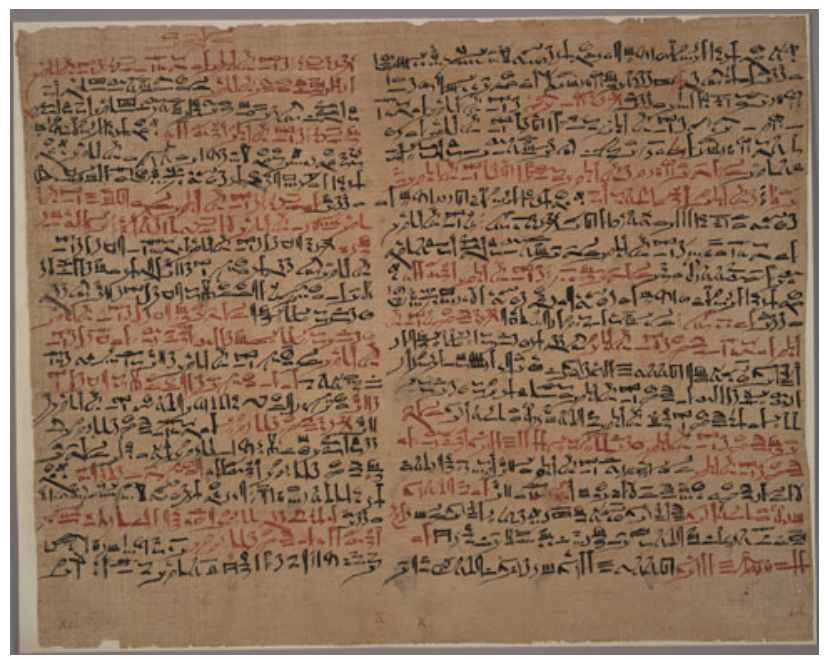

Fig. 1 Plate $\mathrm{X}$ and XI of the Edwin Smith papyrus including the five cervical spinal injury cases in hieratic script [7]

containing the English translation, commentary-along with medical notes prepared by the physician Arno Luckhardt-and hieroglyphic transcription of the original scroll in 1930 [1].

Based on his vast experience and extensive research, Breasted concluded that the papyrus must have been written during the sixteenth century в.c. Interestingly, since the hieroglyphics used in the text were more common in earlier times, around 3,000-2,500 в.C., he-and othersbelieved that the scroll must be a copy of an older text $[1,8]$. This information led to further speculations on the original authorship. Breasted suggested that the Egyptian physician Imhotep, who served under the Third Dynasty of pharaoh Djoser (twentysixth century B.C.), could have been the author of the original text. A recent reappraisal summarized that the papyrus was most likely penned in the seventeenth century в.C. and probably is a copy of an older document. Nonetheless, the original authorship remains a controversial issue [9].

Although his translation of the Edwin Smith papyrus is still regarded as a masterpiece, Breasted encountered several problems in his interpretation of the text. After the publication of his translation in 1930, several other Egyptologists and physicians suggested alternative interpretations of a number of hieroglyphs and fragments written in the original text [10-16]. After thoroughly reinterpreting the original hieratic document, Sanchez and Burridge [9] are currently producing a novel "medically based translation" of the Edwin Smith papyrus. For the clinical appraisal of the spinal injury cases, this latter translation was used for the current review. Before going into detail on the spinal injury cases, it is important to appraise the style and perspective the papyrus was written in.

\section{Style and perspective of the papyrus}

The papyrus includes 48 cases of wounds, injuries and fractures topographically ordered from the skull, neck, upper limbs, chest to the thoracolumbar spine. The text of the last case (case 48) comes to an unexpected end in the middle of a sentence. This suggests that the writer (or writers) was about to write down more cases dealing with wounds and injuries to the thoracolumbar spine, sacrum and lower limbs. The papyrus is astonishingly well structured. Besides the mentioned topographic structure of the scroll, all cases are documented in a similar form. Each case includes the following subheadings: "Introductory heading," "Significant symptoms," "Diagnosis," and-if considered treatable- "Recommended treatment" [9, 10]. Most of the cases also include an additional subheading "Explanation" in which unfamiliar terms used in the case description are clarified.

The "Significant symptoms" section of the cases mostly starts as: "If you examine a man for...". Interestingly, no further characteristics of "the man" or cases under study are provided. It has been suggested that the cases described in the papyrus predominantly concern patients who sustained their injuries during battles or construction work [10, 15, 17-19]. From this perspective, one may assume that the cases under study deal with relatively young, healthy male patients. From another, more modern, point of view the starting fragment may also be interpreted as: "In case of". This means that other (prognostic) factors than the diagnosis under study were not considered in the treatment decision-making. In line with this "In case of"-approach is the finding that in the "Significant symptoms" section the main diagnosis is always reported prior to the underlying clinical signs and symptoms. This order of provided information suggests that the documented cases are not chronological descriptions of the diagnostic work-up of an individual case, but rather accurate, post hoc descriptions of the most significant signs and symptoms of the diagnosis under study.

Another interesting aspect is that none of the cases include differential diagnoses. Nonetheless, since a number of unique cases were documented for most of the regions, i.e. head (27), neck (5), upper arm (3) and chest (8), the papyrus may have guided the differential diagnostic process in those physicians who had the knowledge of the major symptoms of each diagnosis in each region. A similar post hoc approach as in the "Significant symptoms" section can be found in the "Diagnosis section". In each case one of the following three verdicts follows the diagnosis: (1) "(This is) a medical condition I can heal" (2) "(This is) a medical condition I intend to fight with." and (3) "(This is) a medical condition that cannot be healed." This therapeutic rationale, which is still applied in modern 
military triage, shows that the ancient Egyptian physician must have had an enormous experience in the natural history and treatment outcomes of traumatic injuries.

\section{Spinal injuries reported in the papyrus}

Six of the cases documented in the papyrus primarily deal with injuries to the spine (cases 29-33 and 48), see Table 1. The translations of each of these cases are presented in the Appendix [9].

Significant symptoms of spinal injuries

The "significant symptoms" of the spinal injury cases are summarized in Table 1. In one case other information than the signs and symptoms belonging to the diagnosis under study have been documented as well:

Case 33: "it is his fall head-downward which caused a vertebra to crush into its counterpart."

In no other case, the mechanism of injury has been described. In fact, this is the only case presenting information acquired from history taking or, more likely in this case, heteroanamnesis.

Although the symptom "stiffness of the neck" is documented in eleven cases (cases 3-8, 19, 20, 22 and 29), this symptom is reported in only one of the six cases with spinal injury. In the head injury cases, neck stiffness is attributed by the Egyptian physicians to what amounts, in our terms, meningismus from traumatic subarachnoid hemorrhage. The inability to rotate or flex the neck is described in seven cases (cases 4, 5, 7, 19, 29, 30 and 32), of which three cases deal with spinal injury. Whereas the diagnosis of a 'cervical sprain with disc injury' (case 30 ) is associated with the ability to rotate and flex the neck (although painful), the diagnoses "cervical stab wound, perforating a vertebra" and "cervical vertebral compression fracture" (cases 29 and 32 , respectively) are related to the inability to do so.

In case 48 , the only case dealing with a lumbar spinal injury, a unique type of physical examination is reported. The patient, presumably lying in supine position, is asked to extend and contract the legs. When the patients suffer from 'a wrenching/sprain in the vertebral column of lower back with disc injury' he will contract his leg immediately because of the resulting pain of vertebral origin. Interestingly, this is the only clinical symptom reported in this case. Although others hypothesized that this case represents the first description of non-traumatic low back pain [20], this case most likely covers the diagnosis of a symptomatic traumatic lumbar intervertebral disc injury $[21,22]$. In fact, the maneuver described in case 48 can be considered as the clinical precursor of Lasegue's sign [23].
The papyrus includes two cases with spinal cord injury (cases 31 and 33). It is noteworthy that in these two cases significant symptoms related to injuries of the spinal column, e.g. stiffness of the neck and the ability to rotate and bend the neck, are not described at all. All of the reported signs and symptoms are related to the spinal cord injury. One symptom is documented in both cases: "unawareness of both the arms and legs". The use of the term unawareness in this context is intriguing. It implicates that both motor and sensory functions are (completely) absent. After carefully reading case 31 , we can conclude, however, that the accuracy of this description of neurological deficit leaves room to speculation. The following text, which is perhaps one of most interesting fragments of the entire papyrus, explains why:

Case 31: "...it is a dislocation of a vertebra of the back of his neck extending to his thoracic spine, that causes him to be unaware of both his arms and his legs. If however, the middle vertebra of the back of neck is dislocated, ejaculation arises from his penis."

Based on the second sentence, we cannot do otherwise than to conclude this case concerns a spinal injury located at the lower part of the cervical spine resulting in a low cervical tetraplegia $[1,3,6]$. From a modern perspective, we know that the motor and sensory tracts to the proximal parts of the upper limbs (myo- and dermatomes C5) would likely had have been intact in such a case. Therefore, it is plausible to assume that, in case 31, a certain 'awareness' of the upper extremities was preserved.

The papyrus contains the first known descriptions of autonomic dysfunction in spinal cord injury, including: priapism, urinary incontinence and abdominal distention (case 31). The bloodshot eyes (case 31), stupor and aphasia (case 33) are not related to the spinal cord injury as these signs are most likely the result of an inaccurately described closed head injury.

\section{Categorization of spinal injuries}

As mentioned, the papyrus excels by its topographic structure. The categorization of anatomical regions is also observed within the group of spinal injuries. Diagnoses of the cervical spine (cases 29-33) are clearly distinguished from diagnoses of the thoracic and/or lumbar spine (case 48). Furthermore, the cervical spinal injury cases can further be categorized in open (case 29) and closed (cases 30-33) wounds.

Each of the four closed cervical spinal injury cases concerns a unique diagnosis of the injured spinal column. An additional explanation on the diagnosis is provided by the writer in each case (see Appendix). The modern diagnoses, as expressed in the case's titles are 


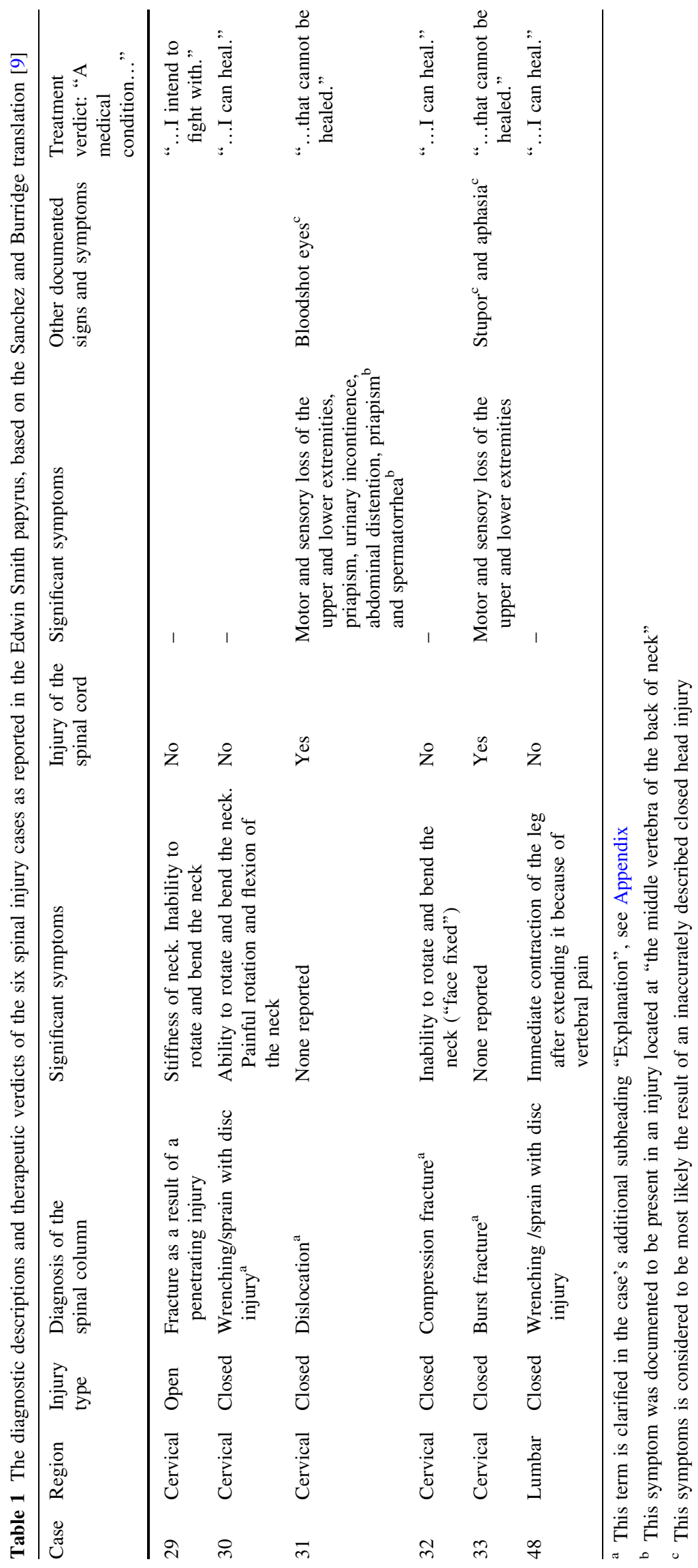


- Case 30: cervical sprain with disc injury;

- Case 31: cervical vertebral dislocation with spinal cord and head injury;

- Case 32: cervical vertebral compression fracture; and

- Case 33: cervical burst fracture with spinal cord injury and brain contusion.

Case 30 represents the least disabling type of spinal injury and has previously been interpreted as a whiplash injury [24]. The case's explanation includes a remarkably detailed description of the lost integrity of the non-synovial intervertebral joint, i.e. the intervertebral disc [9, 21]. Case 31 concerns a more severe injury with separation of one vertebra from another. However, the extent and direction of the displacement injury remain speculative issues. In contrast, the explanation on the vertebral compression fracture accompanying case 32 includes a highly illustrative metaphor:

Case 32: "The inside of the back of his neck is like a foot sinking into cultivated soil; it is a compressing / collapsing downwards".

It is hard to imagine that more than 3,500 years before the publication of Watson-Jones's vertebral body fracture classification, the Egyptian physicians already distinguished vertebral body compression fractures from vertebral body burst fractures [25]. The detailed description of the crushed fracture in case 33 suggests that post-mortem examinations were performed [26, 27]. The same counts for the documented pathologic anatomic relation between the dislocated vertebra and spinal cord in case 31. Other Egyptologists, however, do not support the suggestion of postmortem examinations being performed in Egypt before the fourth century B.C. [21, 28]. Another question that remains is how the writer accurately determined the diagnoses of cases 30 and 32 in surviving subjects.

Although the signs and symptoms of spinal cord injuries reported in cases 31 and 33 are not entirely similar, the author did not clearly categorize the neurological deficits of these two cases into different entities. However, case 31 includes a very interesting remark:

Case 31: "...If however, the middle vertebra of the back of neck is dislocated, ejaculation arises from his penis."

The writer describes a hypothetical alternative clinical presentation: a more cranial injury to the cervical spinal column would result in a different type of neurological sequelae, namely priapism and spermatorrhea. Although it is evident that the ancient Egypt physicians had great knowledge about human physiology and anatomy (see next paragraph), with the currently available knowledge we can say that the documented causal relation between the level of injury and mentioned neurological sequelae is an inaccurate one. Nonetheless, after reappraising the alternative scenario documented in case 31 we may conclude that, referring to the level of injury, the papyrus includes the oldest known categorization of SCI in history (!).

Causal relations in spinal injuries

Clearly, the author of the papyrus was a learned physician and anatomist. Besides the accurately documented diagnoses and their significant symptoms, the scroll also includes the first ever known reporting of causal relations in spinal injuries [26]. Four causal relations are described in the spinal injury cases. In case 33 , the mechanism of injury is related to the type of spinal column injury:

Case 33: “...his falling head downward, upon the vault of his head, forcibly drives one vertebra of the back of his neck into its neighbor."

This sentence demonstrates that even in ancient times, physicians were aware of the effects of excessive axial loadings on the integrity of the vertebral bodies of the spinal column.

One of the most fascinating fragments of the papyrus concern the documentation of the (inexplicit) causal relation between the injury of the spinal column and spinal cord in cases 31 and 33:

Case 31 "... it is a dislocation of a vertebra of the back of his neck extending to his thoracic spine, that causes him to be unaware of both his arms and his legs."

Case 33: "...caused a vertebra to crush into its counterpart and you find he is unaware of both his arms and his legs because of it."

These two causal descriptions illustrate that more than 3,500 years ago physicians already had substantial knowledge about human physiology. They knew that injuries to the spinal column had the potential to result in motor, sensory and functional deficits. Without doubt, it can be stated that the ancient Egyptian physicians were already aware of the vital functions of the spinal cord.

The last causal relation documented in the spinal injury cases is the following:

Case 48: “... He has to contract it immediately because of the pain that it makes in the vertebral column of his back from which he suffers."

In this case, the writer describes a rational explanation for the pain which is evoked by physical examination.

Treatment of spinal injuries

The statements on the treatability of the spinal injury cases are summarized in Table 1. Two of the six spinal injury cases are considered untreatable; cases 31 and 33, the only two cases with a documented spinal cord injury. The open cervical spinal injury documented in case 29 is followed by the verdict: "(This is) a medical condition I intend to fight with." As the clinical signs and symptoms related to the 
spinal column are quite similar to those reported in case 32 , the reticent verdict on the treatment of case 29 is probably based on the risk of a subsequent infection of the open wound. The writer considers the remaining three cases (cases: 30, 32 and 48) as treatable by non-operative means.

\section{The spinal trauma cases placed in a modern clinical and scientific perspective}

To recapitulate, the Edwin Smith papyrus is a unique treatise containing the oldest known descriptions of signs and symptoms of injuries of the spinal column and spinal cord. The scroll can be characterized as a well-structured teaching manual guiding a physician's differential diagnostic process and treatment-decision-making for a range of diagnoses. The papyrus excels in rationality, even more so when considering it originated at the time when written language itself was a recent invention and medicine was at its birth. The cases covered by the papyrus are not likely to represent individual ancient cases, but rather a series of accurately described clinical scenarios based on the clinical knowledge of highly experienced and educationally minded Egyptian physicians. Although the first documented signs of spinal column injuries are-from a modern perspective-fairly non-specific, symptoms of spinal cord injuries have been documented accurately in the scroll. The papyrus contains the first known categorizations of spinal column and spinal cord injuries and covers important clinical prognostic factors which were considered in the treatment decision-making process as reported by the writer.

While all of the spinal injury cases in the papyrus cover injuries to the spinal column, two cases focus on the signs and symptoms of concomitant injury to the spinal cord. Interestingly, in these two cases significant symptoms related to injuries of the spinal column are not described at all. Given the devastating effects of spinal cord injury on survival outcomes, details about injuries to the spinal column and their prognostic value were apparently not considered significant enough to be reported. A possible explanation for this is that patients with spinal cord injury usually had a poor prognosis. Most of the patients died a relative short period after the injury because of pneumonia, urinary tract infections or other complications related to autonomic dysfunction. It was not until the first half of the twentieth century when survival rates increased dramatically because of the introduction of specialized care, prevention of complications and the discovery and use of antibiotics [29-32].

When compared with ancient Egypt, the contemporary diagnostic work-up of spinal column injuries has improved considerably. With the breakthroughs in medical imaging by Roentgen in 1895 (X-rays) and Hounsfield and Cormack in 1971 (computed tomography) physicians became able to estimate the severity of closed spinal column injuries $[33,34]$. Instead of history-taking and physical examinations, imaging techniques became the reference standards in the diagnostic work-up of spinal column injuries. It is, however, painful to conclude that more than 3,500 years after the first known documented categorization of spinal column injuries, no reliable, accurate and validated spinal injury classification system has been introduced and globally endorsed to date $[35,36]$.

In contrast, contemporary classifications of spinal cord injuries are characterized by their high methodological standards. The 'International Standards for Neurological Classification of Spinal Cord Injury', first introduced in 1982 by the American Spinal Injury Association (ASIA), have become the standardized and routinely adopted classification for traumatic SCI [37, 38]. This classification primarily covers the severity of the key clinical features of spinal cord injury, namely the degree of "unawareness of the arms and legs". Although the ancient treatise accurately describes signs of autonomic dysfunction, it was not until recently when a proposal for 'International standards to document remaining autonomic function after spinal cord injury' was introduced [39].

Since the ancient Egyptian times, the number of effective treatment options for spinal column injuries improved considerably [40-42]. Whereas natural history and treatment outcomes are hardly documented in the papyrus, current spinal trauma literature is actually focused on treatment outcomes of both operatively and non-operatively treated patients. It is fascinating to see the shift of treatment goals over time. Whereas ancient Egyptian triage medicine considered the likelihood of survival as the most important outcome of interest, nowadays the quality of life and functional outcome measures are of primary interest $[43,44]$. Despite all recent scientific efforts, a cure for spinal cord injury still does not exist. Nonetheless, the treatment verdict "(This is) a medical condition that cannot be healed." lost terrain since the care of spinal cord injuries improved considerably during the last century.

With a number of causal relations described in the spinal injury cases the Edwin Smith papyrus excels in rationality. Moreover, the most significant symptoms were explicitly considered as important prognostic factors in the postulation of the treatment verdicts. As the "study population" of the papyrus most likely included young and healthy male warriors or construction workers, Egyptian physicians probably seldom dealt with other significant, physical prognostic factors influencing treatment decision-making. Although injuries reported in the papyrus still occur today, the distribution of spinal injuries now ranges from children to octogenarians, with the latter group readily increasing 
[45]. Because of this demographic switch of spinal injuries, physicians are nowadays facing more complex diagnostic and therapeutic work ups. Nonetheless, whereas demographics, diagnostic techniques and therapeutic options changed over time, the diagnostic, prognostic and therapeutic rationale documented in the oldest known treasure on spinal injuries can still be considered as the state-of-theart reasoning for modern clinical practice.

Open Access This article is distributed under the terms of the Creative Commons Attribution Noncommercial License which permits any noncommercial use, distribution, and reproduction in any medium, provided the original author(s) and source are credited.

\section{Appendix: the six spinal injury cases documented in the Edwin Smith papyrus [9]}

Case \#29: Cervical stab wound, perforating a vertebra

Title Treatment instructions concerning a knife wound in a vertebra in the back of his neck.

Examination If you should examine a man with a flesh wound because of a knife slash in a vertebra in the back of his neck, penetrating to the bone and perforating the bone of a vertebra of the back of his neck: if when you clean out that oozing wound, take note: the shuddering/wincing because of it is great! He has found he is unable to look at both his shoulders and his chest.

Diagnosis Then you are to say about it: "A wound of the flesh in the back of his neck, penetrating to the bone and perforating the bone of a vertebra in the back of his neck, and one who suffers from rigidity in the back of his neck: (this is) a medical condition I intend to fight with".

Treatment You should bind it over fresh meat the first day. Afterward, lay (him) down on his resting place/camp bed, until the critical period of his affliction passes.

Case \#30: Cervical sprain with disc injury

Title Treatment instructions for a wrenching / sprain in the vertebral column of the back of his neck.

Examination If you should examine a man for a wrenching/sprain in the vertebral column of the back of his neck, then you are to say to him: "Look towards both your shoulders and your chest". When he does so, the 'looking' he is capable of, is painful.

Diagnosis Then you are to say to him: "one who suffers from a wrenching/sprain in the vertebral column of the back of his neck (this is) a medical condition I can heal".

Treatment You have to bind it over fresh meat the first day. Afterward, you should treat with (powdered) alum and honey every day until he recovers.
Explanation As for 'the wrenching/sprain', he says about the wrenching apart in intervertebral joints: "Each vertebra is (still) in its place".

Case \#31: Cervical vertebral dislocation with spinal cord and head injury

Title Treatment instructions for a dislocation in the vertebral column of the back of the neck.

Examination If you should examine a man for a dislocation in the vertebral column of the back of his neck, and you find him unaware of both his arms and his legs, as a result of it, while his penis is stiff because of it and urine drips from his penis without him knowing it and his internal organs have become gaseous and both his eyes are bloodshot, it is a dislocation of the vertebral column of the back of his neck extending to his thoracic spine, that causes him to be unaware of both his arms and his legs. If however, the middle vertebra of the back of neck is dislocated, an involuntary discharge/ejaculation arises from his penis.

Diagnosis Then you are to say about him: "one who has a dislocation in the vertebral column of the back of his neck and he is unaware of his legs and his arms and his urine dribbles: (this is) a medical condition that cannot be healed".

Explanation A As for 'a dislocation in the vertebral column of the back of his neck', he is speaking about one vertebra of the back of his neck separating from its counterpart, the flesh that is on it being sound, like saying: 'it is dislocated' about things which had been joined together until the time one is detached from its counterpart.

Explanation B As for the 'involuntary discharge/ejaculation' it refers to what is occurring with regard to his penis. His penis is stiff and subject to emission from the end of his phallus. That is to say, the penis remains stationary, it does not move down to the genital region, moreover, neither can it lift upward.

Explanation $C$ As for 'the weakness of his urine', it means that urine drips from his penis and does not hold back for him.

Case \#32: Cervical vertebral compression fracture

Title Treatment instructions for a subsidence in a vertebra in the back of his neck.

Examination If you should examine a man for a subsidence in a vertebra in the back of his neck and his face is fixed and he cannot turn his neck, you must say to him: "Look to the front of your chest and to your two shoulder joints". Then he finds he is unable to turn his face. He can look to neither the front of his chest nor his two shoulder joints. 
Diagnosis Then you are to say about him: "one who has a subsidence in a vertebra in the back of his neck (this is) a medical condition I can heal".

Treatment You have to bind it over fresh meat the first day. You have to loosen his bandages, and you then apply ointment to his head as far as the back of his neck. You have to bandage it over alum and you should treat him afterward with honey every day. It means his treatment protocol is 'sitting upright' until he recovers.

Explanation As for 'a subsidence in a vertebra of the back of his neck', he says, concerning the depressing of a vertebra of the back of his neck: "The inside of the back of his neck is like a foot sinking into cultivated soil; it is a compressing/collapsing downwards".

Case \#33: Cervical burst fracture with spinal cord injury and brain contusion

Title Treatment instructions concerning a crushed vertebra of the back of his neck.

Examination If you should examine a man having a crushed vertebra in the back of neck and you find him with one vertebra fallen into its counterpart, and now he is stuporous and he does not speak. It is his fall head downward which caused a vertebra to crush into its counterpart and you find he is unaware of both his arms and his legs because of it.

Diagnosis Then you are to say about him: "One who has a crushed vertebra in the back of his neck, and he is unaware of both his arms and legs, and is stuporous (this is) a medical condition that cannot be healed".

Explanation A As for 'a crushed vertebra in the back of his neck', he says concerning the falling of one vertebra of the back of his neck into its counterpart, "It is one entering into the other one without moving back and forth".

Explanation B As for 'it is his fall head downward, that is what caused one vertebra to crush into its counterpart', it means, his falling head downward, upon the vault of his head, forcibly drives one vertebra of the back neck into its counterpart.

Case \#48: Sprain in the vertebral column of the lower back with disc injury

Title Treatment instructions for a wrenching / sprain in the vertebral column in his lower back.

Examination If you should examine a wrenching/sprain in the vertebral column of lower back, then you are to say to him: "Please extend your legs". "Contract it". Then he must extend it. He has to contract it immediately because of the pain that it makes in the vertebral column of his back from which he suffers. Then you are to say to him: "One who has a wrenching/sprain in the vertebral column of his lower back (this is) a medical condition I can heal".

Treatment You must lay him stretched out/prostrate and prepare for him...

\section{References}

1. Breasted JH (1930) The Edwin Smith Surgical papyrus (facsimile and hieroglyphic transliteration with translation and commentary, in two volumes). The University of Chicago Press, Chicago

2. Bardinet T (1995) Les papyrus Médicaux de l'Égypte Pharaonique. Fayard, Paris

3. Ebbell B (1939) Die alt-ägyptische Chirurgie: die chirurgischen Abschnitte der Papyrus E. Smith und Papyrus Ebers. Skrifter utgitt av det Norske videnskaps-akademi i Oslo. II. Hist.-filos. Klasse, vol 2. Dybwad, Oslo

4. von Deines H, Grapow H, Westendorf W (1958) Übersetzung der medizinischen Texte, vol IV, 1. Akademie-Verlag, Berlin

5. Westendorf W (1966) Ein Medizinisches Lehrbuch aus dem alten Ägypten. Wund und Unfallchirurgie, Zaubersprüche gegen Seuchen, verschiedene Rezepte. Aus dem Altägyptischen übersetzt und herausgegeben. Hans Huber, Bern

6. Westendorf W (1998) Papyrus Smith. Handbuch der altägyptischen Medizin 2 Band. Brill, Leiden

7. The US National Library of Medicine Turning the Pages Information System (TTPI). Available at http://archive.nlm.nih.gov/ proj/ttp/smith_home.html, Accessed 17 May 2010

8. Dévaud E (1924) L'age des papyrus égyptiens hiératiques d'après les graphics de certains mots de la XII-e dvnastie à la fin de la XVIII-e dynastie. Paul Geuthner, Paris

9. Sanchez GM, Burridge AL The Edwin Smith papyrus. A medically based translation from the original ancient Egyptian hieratic document (in preparation)

10. Sanchez GM, Burridge AL (2007) Decision making in head injury management in the Edwin Smith papyrus. Neurosurg Focus 23(1):E5

11. Brawanski A (2001) Die Fälle 1-8 des Papyrus Edwin Smith ("Schädelhirntraumafälle"). Studien zur Altägyptischen Kultur 29:7-39

12. Brawanski A (2004) Die Wirbelsäulenverletzungen des Papyrus Edwin Smith (Fall 29-33). Studien zur Altägyptischen Kultur 32:59-80

13. Cave AJE (1937) The antiquity of vertebral nomenclature. In: Proceedings of the anatomical society of Great Britain and Ireland, December 1936-July 1937. J Anat 72(Pt 1):169-173

14. Ralston BL (1977) Medical reinterpretation of case four of the Edwin Smith surgical papyrus. J Egypt Archaeol 63:116-121

15. Risse GB (1972) Rational Egyptian surgery: a cranial injury discussed in the Edwin Smith papyrus. Bull N Y Acad Med 48(7):912-919

16. Wilson JA (1952) A note on the Edwin Smith surgical papyrus. J Near East Stud 11(1):76-80

17. McCallum JE (2008) Egyptian military medicine. In: Military medicine: from ancient times to the 21st century. ABC-CLIO, Santa Barbara, pp 111-113

18. Schneider SP (2001) Musculoskeletal injuries in construction: a review of the literature. Appl Occup Environ Hyg 16(11): 1056-1064

19. Brandt-Rauf PW, Brandt-Rauf SI (1987) History of occupational medicine: relevance of Imhotep and the Edwin Smith papyrus. Br J Ind Med 44(1):68-70 
20. Allan DB, Waddell G (1989) An historical perspective on low back pain and disability. Acta Orthop Scand Suppl 234:1-23

21. Walker JH (1996) Studies in ancient Egyptian anatomical terminology, The Australian Centre for Egyptology: Studies 4. Aris and Phillips Ltd., Warminster

22. Lang JK, Kolenda H (2002) First appearance and sense of the term "spinal column" in ancient Egypt. Historical vignette. J Neurosurg 97(1 Suppl):152-155

23. Pahor AL (1992) Ear, nose and throat in ancient Egypt: part III. J Laryngol Otol 106(10):863-873

24. Bannister G, Amirfeyz R, Kelley S, Gargan M (2009) Whiplash injury. J Bone Joint Surg Br 91(7):845-850

25. Watson-Jones R (1938) The results of postural reduction of fractures of the spine. J Bone Joint Surg Am 20(3):567-586

26. Inskeep RR (1969) Health hazards and healing in antiquity. S Afr Archaeol Bull 24(93):21-29

27. Rowling JT (1986) Some speculations on the use and decline of surgery in dynastic Egypt. In: David AR (ed) Science in Egyptology. Manchester University Press, Manchester

28. Nunn JF (1966) Ancient Egyptian medicine. University of Oklahoma Press, Norman

29. Chain E, Florey HW, Gardner AD, Heatley NG, Jennings MA, Orr-Ewing J et al (1940) Penicillin as a chemotherapeutic agent. Lancet 236(6104):226-228

30. Fleming A (1929) On the antibacterial action of cultures of a Penicillium with special reference to their use in the isolation of B. influenzae. Br J Exp Pathol 10:226-236

31. Guttmann L (1946) Rehabilitation after injuries to the spinal cord and cauda equina. Br J Phys Med 9(6):162-171

32. Munro D (1947) The rehabilitation of patients totally paralyzed below the waist, with special reference to making them ambulatory and capable of earning their living. $N$ Engl $\mathrm{J}$ Med 236(7):223-235

33. Hounsfield GN (1973) Computerized transverse axial scanning (tomography). 1. Description of system. $\mathrm{Br} \quad \mathrm{J}$ Radiol 46(552):1016-1022
34. Roentgen WC. Uber eine neue art von strahlen: vorlaufige mitteilung. Sitzungs Berichte der Physikalisch-Medizinischen Gesellschaft in Wurzburg 1895(137):132-141

35. van Middendorp JJ, Audige L, Hanson B, Chapman JR, Hosman AJ (2010) What should an ideal spinal injury classification system consist of? A methodological review and conceptual proposal for future classifications. Eur Spine J (E-pub ahead of print)

36. Chapman JR, Dettori JR, Norvell DC (eds) (2009) Spine classifications and severity measures, 1st edn. Thieme Verlag, New York

37. American Spinal Injury Association (1982) Standards for neurological classification of spinal injured patients. American Spinal Injury Association, Chicago

38. American Spinal Injury Association (2003) International standards for neurological classification of spinal cord injury, revised 2003. American Spinal Injury Association, Chicago

39. Alexander MS, Biering-Sorensen F, Bodner D, Brackett NL, Cardenas D, Charlifue S et al (2009) International standards to document remaining autonomic function after spinal cord injury. Spinal Cord 47(1):36-43

40. Goodrich JT (2004) History of spine surgery in the ancient and medieval worlds. Neurosurg Focus 16(1):E2

41. Goodrich JT (2007) Cervical spine surgery in the ancient and medieval worlds. Neurosurg Focus 23(1):E7

42. Knoeller SM, Seifried C (2000) Historical perspective: history of spinal surgery. Spine (Phila Pa 1976) 25(21):2838-2843

43. Alexander MS, Anderson KD, Biering-Sorensen F, Blight AR, Brannon R, Bryce TN et al (2009) Outcome measures in spinal cord injury: recent assessments and recommendations for future directions. Spinal Cord 47(8):582-591

44. Chapman JR, Hanson B, Dettori JR, Norvell DC (eds) (2007) Spine outcomes measures and instruments, 1st edn. Thieme Verlag, New York

45. (2003) Trends in aging-United States and worldwide. MMWR Morb Mortal Wkly Rep 52(6):101-104, 106 